\title{
THE KARDASHIAN COMPLEX: PERFORMING SEXUALITY AND FEMININITY THROUGH IMAGE AND SCREENS
}

Tyla Stevenson

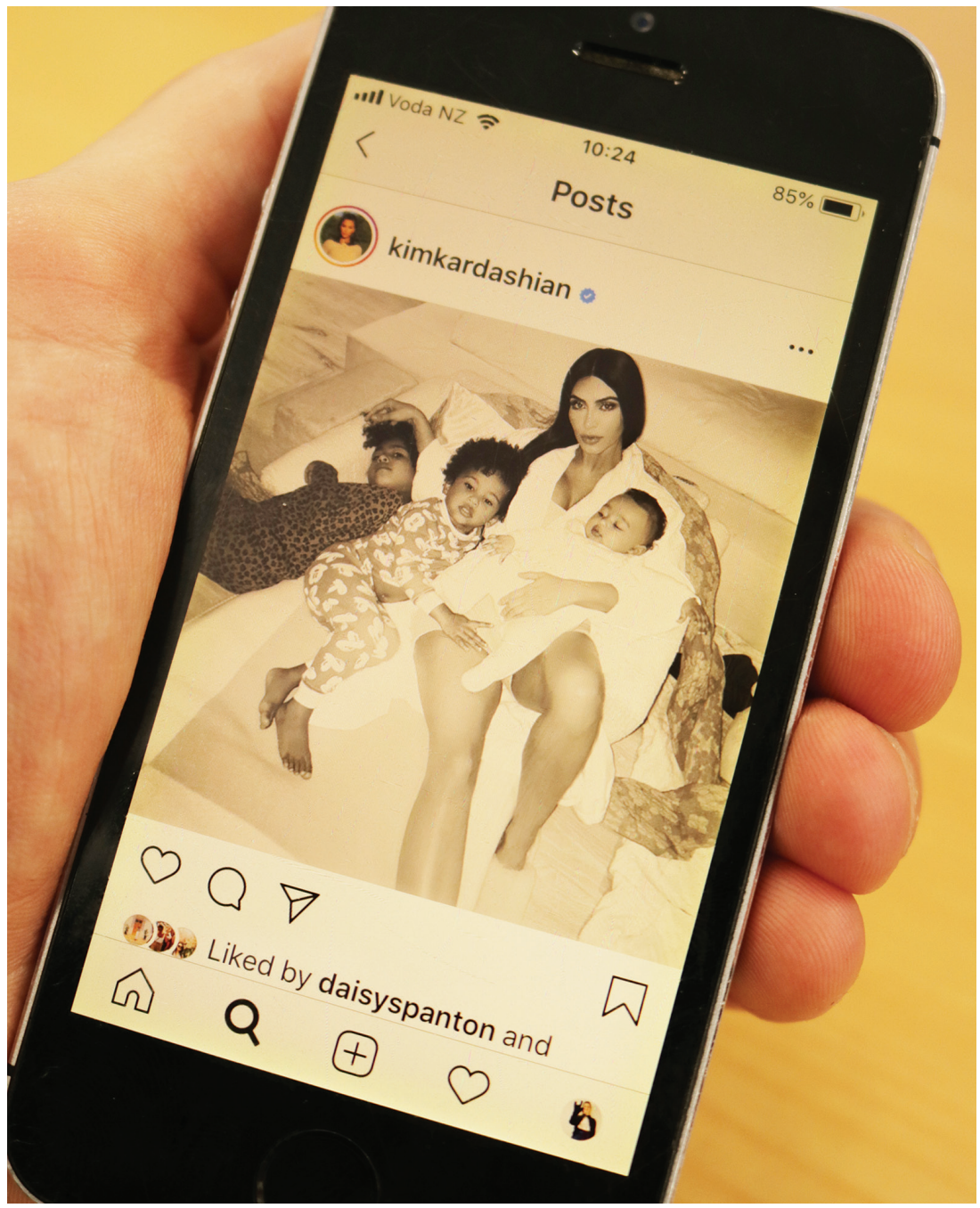

Figure I. technology such as smartphones have increasingly enabled the performativity of a diverse range of femininities, as well as affording control of their representation and dissemination by their subjects. 
Fashion as we understand it, is an umbrella term which envelops the in numerous ideas and domains within the broader industry. Within the present technological and political climate, the way clothing, garments and fashion are primarily consumed and disseminated, is through second hand and first hand interactions-with an abundance of different communicative technologies, including of course, online media. This paper focuses on the contemporary fashion image specifically that of viral online content attached to Kim Kardashian's Instagram account. With the number of those who have regular access to the internet and mobile devices continuing to rise, the production of the 'fashion image', and its reterritorialization back into the world is easier and faster than ever before. Because of the rise and accessibility of fashion image making, it is crucial we analyse it's production-specifically in the way that women's bodies are appropriated and beauty ideals are portrayed. Laura Mulvey, throughout multiple scholarly texts, suggests that women are often positioned to be considered as objects to be consumed, desired or looked at.' However, I would suggest that there are limitations to this analysis being applied to a 2 Ist century fashion image making model, in a culture of complex feminist performativity.

Emphasis can be made on the materiality of the fashion garment, but the physical fashion garment and its virtual image coexist and cooperate in a synonymous way. As an example,Vogue have been producing fashion images since their conception in 1892, through illustration, photography and film. The ever-changing technological environment, has always entangled itself with and informed the way fashion and its image is disseminated and experienced. No longer does the industry rely on the fashion magazine and its tangible media to disperse and regulate industry content. Producing digital fashion photography and film online is not only an effective way of capturing a collection or the essence of a design, but also a productive and effective advertising tool. The way we interpret audience engagement with the product has shifted since the accessibility to online content. As Karaminas explains,

"Computer based imagery and mobile media have brought another dimension to the circulation and understanding of meaning and its impact on audience reception... where once fashion photography relied, or two dimensional print media, relied on the image to seduce the audience into purchasing a garment by constructing a narrative of desire digital media immerses the audience into the desired world of the luxury brand by evoking visual and olfactory pleasure."'

Although Karaminas has opened a critical field of enquiry into the investigation and analysis of the digitisation of the fashion image online, what remains mostly unexplored in the conversation is that digital media and the advancement of technology has offered a new understanding of the role of image, moving or still and its relationship to the active participant and spectator, now that its common and popular for the subject of an image to also be its creator.

There are multiple facets to online image sharing. One of the most prominent platforms for sharing images is the social media network Instagram. Instagram is a network that is embedded into your smartphone, enabling users to post their own content any time. Users follow each other, providing 'likes' for favourable content. Instagram as a social media site has doubled its user accounts in the past two years, with 800 million active users.

A popular form of content posted on Instagram is the 'selfie'; a form of self-portraiture taken with the users smartphone camera. With the rising accessibility to the internet, use of smartphones and social media, more people have the opportunity to circulate their image and it is important to analyse the content of these images. How are these images produced, and by who? Who or what is assigned the most autonomy and validation within communicative media? Usually when discussing ideas surrounding the way women are portrayed through image and media, blame is often directed at content creators for fashion media such as photographers, magazines and advertisements for promoting homoginist, stereotypical and unrealistic beauty standards. But when it is the public that are producing the images, who are also the subjects of the image, can we apply a similar critique?

Mulvey's famous academic text Visual Pleasure and Narrative Cinema was published in 1973. Her analysis of Hollywood cinema during the 70's doesn't consider the types of technological changes we have today, but the way 
Hollywood cinema is consumed and enjoyed within the 2 I st century doesn't veer far from its earliest conception. Regardless a summary of Mulveys analysis of classical cinema is needed as it is still being used to critique and analyse the role women play in contemporary still and moving image.

Men are empowered as the subject of the male gaze, while the female, as object, exists in order to be viewed. ${ }^{3}$ Mulvey argues men can identify with the active role of the subjective protagonist that thereby generates a sense of agency, which women don't achieve as the objectified other. Instead, it is implied, women are positioned in an exhibition to be looked at, with their appearance associated with coded erotic visuals. This split between the active protagonist male, and the sexually coded, passive female determines the male gaze, a projection of fantasy onto the female figure. Camera shots and editing features are styled accordingly, objectifying the female character, panning up and down her female figure and dissecting the body into fragmented pieces when moving in for close-ups. ${ }^{4}$

The male gaze concept has been used as a way to critique the way social media is being used to hypersexualise young women and their bodies, and notes, that new technologies and digital reproduction have made the consumption of women's bodies even more accessible than ever before. ${ }^{5}$ Maintaining that the proliferation of images of people (including celebrities) mean they are more widely available for public consumption. Authors such as Kelly Oliver argues that social media outlets such as Instagram were invented within a culture of the male gaze, formulated to reinforce it. ${ }^{6}$ Suggesting that the images women produce of themselves in various seductive poses, which they then post onto their social media accounts such as Instagram and Facebook, re-create the male gaze objectification onto themselves.

There is however little indication throughout Oliver's or Muveys texts that women can be in control of their own image production when operating webcams, camera phones and other online internet based technologies. This is an important reconceptualisation of the male gaze critique in the age of social media and image sharing, and one presented by Michele White. ${ }^{7}$ White suggests that we can use feminist analysis that doesn't simply imply that visual media is always taking part in a process that assumes viewers look upon and possess women's bodies in a relationship of the subject objectifying the object. ${ }^{8}$ White presents the webcam operator as an example of women using computer technologies and the virtual image to make themselves and their bodies visible in a controlled way. While webcams have the potential to reinforce gender norms regarding performing eroticism for the voyeur, women have heightened control over their image making and the manner of its representation. ${ }^{9}$

The webcam user and the use of a front facing camera is synonymous with online media and the exchange and production of moving and still images. While it provides a site to begin theorising a different set of concepts around spectatorship and the gaze, specifically the ways in which webcam operators have the subjectivity to gaze back. Within the world of webcam operating, the operators and their spectators can resist the binary logic of man/active, women/passive of classical cinema and the image produced by the webcam operator is often too fragmented, skewed often due to the closeness of the body to the cam, for voyeurism to enact properly. White suggests that "...the promised reality of webcams is also distributed by the overt camera processes, varied website elements, blurred, or static infused views, and webcam operators who refuse to meet the spectators demand". ${ }^{\prime}$ I suggest that there are positive political aspects of women's webcams which include the operator's defiant modes of address and resistance to fully producing images for the male gaze. It is useful to consider how the gaze is sometimes disrupted in an internet setting, even if all not all spectators notice this. The idea that this medium or Instagram is manufactured by and for men prevents an extensive understanding of women's active role in using online media and producing images of female representation.

The Kardashian's, a multibillion dollar matriarchy of socialites, is an example of a business selling both their bodies and sexualities to their fans and followers. Kim Kardashian, the face of the family brand was reportedly as the most Google searched person of 20 I5. Kim has III million Instagram followers, and with the other family members not far behind it is easy to understand the scale of their fame. 
Since the launch of their reality show, Keeping Up with the Kardashian's in 2007 the Kardashians have been commodifying the idea of the unconventional modern family. Their loyalty, love-lives, wealth, consumption, fame, bodies and sexuality are exploited for profit and played out on the national and international stage. While it would be easy to argue that the overt hyper sexuality of the Kardashian brand is another example of the media presenting women as dependant ornaments to be looked at and sexually desired, the Kardashian's can in fact be considered a group of women utilizing their bodies and sexualities to achieve their career and financial goals. Kim Kardashian in particular, has used Instagram and other social media as a smart marketing strategy. Through control of her image making, Kim performs an erotic hyper sexuality, simultaneously establishing conservative family values, thereby constructing an image of herself as both "the Madonna and the whore."'

American women in the public eye haven't always had the agency to control their image and content like the Kardashians have. While Kim, for example, is able to choose how she wants to portray herself from day to day, be it an erotic, bedazzled bikini, bathroom selfie or a family picture on vacation. This amount of control over the dissemination of the personal imagery of star-like celebrities would have been unheard of throughout the developing Hollywood star system of the 1930's and 40's. Performers before this time were somewhat anonymous, and as audiences showed interest in knowing the people behind the characters, studios realised that the star's identities were now marketable. By this stage film studios had arranged limiting contracts with their talent that put their publicity departments in authority over their image construction and dissemination. Giving the star no option to terminate or any legal right to break their contract often reflected a one sided operation in favour of the studios. ${ }^{12}$ Due to the development of the smartphone Kim Kardashian and contemporary stars alike are able to take on a more DIY approach to their image dissemination, often opting to use the selfie that shows, both figuratively and literally, full autonomy over their image making. It would be naive to say that the contemporary Hollywood star system is now a democratised organization with stars in complete power over their image and opportunities, as well as it is ingenuous to assume that a celebrity like Kim Kardashian doesn't have authority of her body, image and its intended use.

The Kardashian clan use a variety of styling, lighting, photography, video, written word and careful content management to present themselves and their brand to their fans and millions of followers. They epitomize contemporary ideas of the American dream through their diligent entrepreneurial spirit, cultivating their image through social media and the idea of the celebrity, which they maintain through their online presence with their fans. Kim Kardashian has successfully appealed to a variety of markets, all genders, age groups, economic class both liberal and conservative. McClain maintains "Their branding and celebrity empire would not exist without the smart use of social media. Their usage is an exemplar of how to buttress popularity, extend celebrity, and associate image and products. The Kardashian's are a prototype of how social media usage can be used to attain the American Dream of success" (I32). ${ }^{13}$

Kim and the Kardashian family overtly benefit from their own exploitation. To take a surface-level reading we could come to the conclusion that the commodification of their hyper sexuality implies that to attain similar success, the consumption of specific fashion and beauty products is needed. Kim and the Kardashian family solidify their own beauty and fashion brands (Dash Boutique, KKW Beauty and Fragrance, Kylie Cosmetics) by living in them, therefore associating their lifestyle with their product. In Kardashian Komplicity: Performing Post Feminist Beauty, Giulinana Monteverde explains how the Kardashian's are often criticised by feminists of projecting complicit behaviours favouring oppressive body and beauty standards. ${ }^{14}$ Rather than the author simply regarding the Kardashian's involvement within the fashion and beauty industry as oppressive or superficial however, Monteverde instead suggests that they are reinforcing a neo-liberal logic. Montevede explains how "interactions with beauty are not necessarily evidence of patriarchal victimhood". ${ }^{5}$ It is important to avoid generating assumptions that women who engage with beauty standards are complicit in their own oppression. There are various feminist critique of beauty culture that are valid, but there are also examples of beauty practices being useful for the subversion of gender performance and sexuality. There are numerous reasons why people engage with beauty practices, and one cannot assume it is in favour of essentialist heteronormative gendered system. 
In many ways Kim Kardashian reflects a type of raunch culture and "do-me" that can be considered as a combination of somewhat conflicting feminist ideologies. Those that engage with this culture use provocative appearance and behaviour as acts of female liberation and empowerment, often through overtly sex positive attitudes. ${ }^{16}$ It is undermining those that engage in beauty practices to assume they undertake this appearance to please or attract men. Taking control of their femininity and sexuality complicates the idea of the male gaze, and is then aligned with ideas of "female emancipation and self-determination rather than its previous connotations of patriarchal oppression and subjugation." ${ }^{\prime 7}$ To align sex positivity and active hyper sexuality with anti-feminist ideology is regressive, when in reality these ideas are related to feminist core issues such as the right to choose what individuals can do with their own bodies. But when it comes to a celebrity mother like Kim Kardashian, posting images of her own body to her Instagram, account the media is quick to obsess with her feminist intentions.

To progress from the black and white binaristic thinking of previous feminist waves, critics need to open themselves up to other modes of thinking and to re-evaluate what would previously be labelled as anti-feminist; we need to adapt our modes of thinking alongside technological changes. To apply a critique of classical cinema to, say, an Instagram selfie, is ignoring its critical potential, and reveals its irrelevance. Instead, promotion of a politics of ambiguity is necessary to articulate the complex negotiations between sexual objectification and liberation. ${ }^{18}$ While it would be easy and convenient to assume that sexual subjectification is an oppressive media ploy adopted by virtual women, we need to also acknowledge the opportunity to renegotiate notions of feminine sexuality. It might be useful to consider adopting traditionally contradictory modes of feminism to understand and produce more nuanced reading of 2 Ist century expressions of sexual and feminine identities.

The analysis of the fashion image isn't as simple as blaming the hyper sexualisation of women on fashion industry media. Women are subject to their own image making, and it's not helpful to project historical feminist ideals onto these women, as modern feminism is a fluid and intersectional apparatus, that deserves the time and acknowledgement of how complex these ideas and identities can be. I want to acknowledge the meaninglessness of labelling Kim, the Kardashian clan or other celebrities alike as 'feminist' or 'anti-feminist'. To do so is to ignore the nuances of feminine performativity. Feminine identities of the new millennium are always in a constant in-between space or flux between the bound and unbound.

Tyla Stevenson is a Wellington based fashion design graduate with a research interest in the implications of new technologies, the internet and online media on the fashion system, identity and the body. The basis of this paper was presented at the 2018 Costume and Textile Association of New Zealand (CTANZ) symposium Unbound: Liberating Women. 
I Mulvey, Laura. “Visual pleasure and narrative cinema." In Visual and other pleasures, pp. 14-26. Palgrave Macmillan, London, 1989.

2 Karaminas, Vicki. "Image: Fashionscapes- Notes Toward an Understanding of Media Technologies and Their Impact on Contemporary Fashion Imagery." In Geczy, Adam, and Vicki Karaminas, (eds.) Fashion and Art (Bloomsbury: London and New York, 2013) 180.

3 White, Michele. The Body and the Screen:Theories of Internet Spectatorship. (MIT Press: Cambridge, MA, 2006). 70.

4 Oliver, Kelly. "The Male Gaze Is More Relevant, and More Dangerous, than Ever." New Review of Film and Television Studies, vol. I5, no. 4, (Feb. 2017), 452.

5 Oliver. "The Male Gaze Is More Relevant, and More Dangerous, than Ever." 452.

6 Oliver. "The Male Gaze Is More Relevant, and More Dangerous, than Ever." 453-4.

7 White, Michele. The Body and the Screen:Theories of Internet Spectatorship. (MIT Press: Cambridge, MA, 2006).

8 White. The Body and the Screen. 59.

9 White. The Body and the Screen. 59.

10 White. The Body and the Screen. 58

II McClain, Amanda Scheiner. Keeping up the Kardashian Brand: Celebrity, Materialism, and Sexuality. (Lexington Books: Plymouth, UK, 2015) 58.

12 McDonald, Paul. The Star System: Hollywood's production of popular identities. (London:Wallflower, 20I I).

13 McClain. Keeping up the Kardashian Brand, 132.

I4 Monteverde, Giuliana. "Kardashian Komplicity: Performing Post-Feminist Beauty." Critical Studies in Fashion \& Beauty, vol. 7, no. 2, Jan. 2016, pp. I53-172.

15 Monteverde. "Kardashian Komplicity: Performing Post-Feminist Beauty." I 56.

16 Genz Stéphanie, and Benjamin A. Brabon. Postfeminism: Cultural Texts and Theories. (Edinburgh University Press: Edinburgh, 2018) 91.

17 Genz and Brabon. Postfeminism. 93.

18 Genz and Brabon. Postfeminism. 97. 